\title{
Unexpected diagnosis in a patient with a left ventricular assist device: rectal cancer
}

Ulaş Aday, Ebubekir Gündeş, Durmuş Ali Çetin, Hüseyin Çiyiltepe, Erdal Polat

Department of Gastroenterological Surgery, Kartal Koşuyolu High Specialized Training and Research Hospital, Kartal, Istanbul, Turkey

Submitted: 18 June 2017

Accepted: 21 July 2017

Arch Med Sci Atheroscler Dis 2017; 2: e31-e33

DOI: https://doi.org/10.5114/amsad.2017.70497

Copyright $\odot 2017$ Termedia \& Banach

Left ventricular assist devices (LVADs) are being increasingly used in end-stage cardiac failures. Two-year survival rates have gone up to about $70 \%$ thanks to these devices used as a bridge for heart transplantations or destination treatment. Long survival times provided by LVAD support the increased frequency of noncardiac surgical procedures in these patients [1]. This study presents the case of a patient who underwent LVAD insertion while waiting for heart transplantation because of dilated cardiomyopathy followed by administration of multidisciplinary treatment for rectal cancer.

The 54-year-old male patient was followed up by our hospital's organ transplantation clinic as he developed decompensated heart failure while he was being followed up with a dilated cardiomyopathy diagnosis. As the patient's stabilization could not be achieved by medical treatment, a HeartMate II (Thoratec Corp, Pleasanton, CA, USA) ventricular support device was inserted in order to obtain bridging to heart transplantation. Two weeks after the insertion of the HeartMate II device and the initiation of warfarin and acetyl salicylic acid (ASA) administration, a mass was detected in the mid-rectum during the colonoscopic evaluation carried out because of fresh rectal bleeding. The patient's biopsy results revealed adenocarcinoma and his radiological evaluation indicated that it was a locally advanced stage $(\mathrm{cT} 3 \mathrm{~N}+)$ (Figure 1). The patient was taken off the transplantation waiting list. Six weeks after the patient received neoadjuvant chemoradiotherapy (CRT), the Hartmann procedure was performed under general anesthesia. The drive lines did not prevent the midline incision as shown in Figure 2. The total duration of surgery was 210 min, while the amount of measured blood loss was $240 \mathrm{ml}$. Neither intraoperative inotrope support nor blood and fresh frozen plasma transfusion was needed. The patient contracted a pelvic abscess due to rectal stump leak during the post-operative follow-up period (Figure 3). Surgical drainage was performed because percutaneous drainage and antibiotherapy failed. The patient was discharged on the $29^{\text {th }}$ post-operative day. As his final pathological evaluation showed T3N2 (stage IIIC), adjuvant chemotherapy was initiated. A metastasis measuring about $3 \mathrm{~cm}$ was detected in hepatic segment 4A during the $25^{\text {th }}$ month of follow-up (Figure 4). Although the tumor was viable for resection, the patient received radiofrequency ablation therapy because of his current comorbidity and his own preference. The patient died in the $29^{\text {th }}$ month of follow-up because of multiorgan failure.

\author{
Corresponding author: \\ Ulaş Aday \\ Department of \\ Gastroenterological Surgery \\ Kartal Koşuyolu \\ High Specialized \\ Training and Research \\ Hospital, Kartal \\ 34685 Istanbul, Turkey \\ Phone: +90 5302933895 \\ E-mail: ulasaday@gmail.com
}




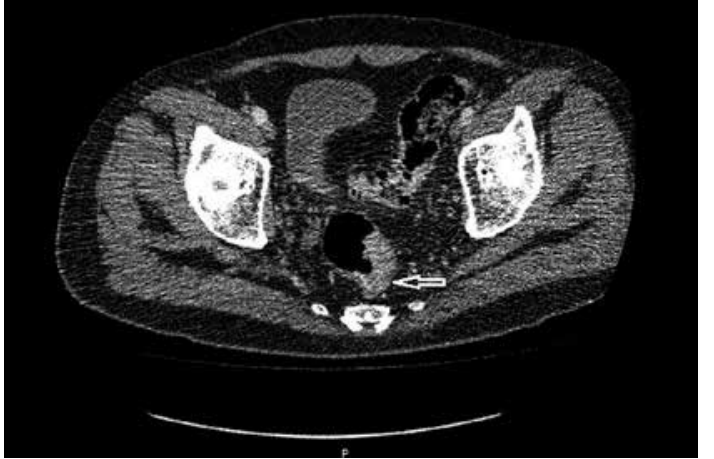

Figure 1. Computed tomography image of rectal cancer

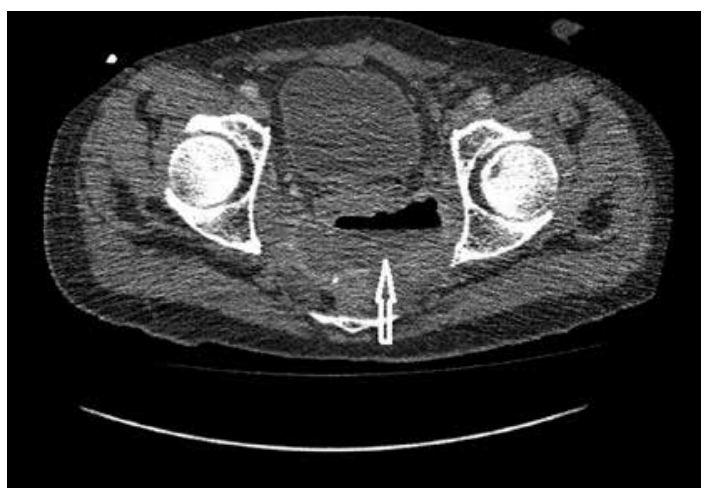

Figure 3. Computed tomography image of pelvic abscess

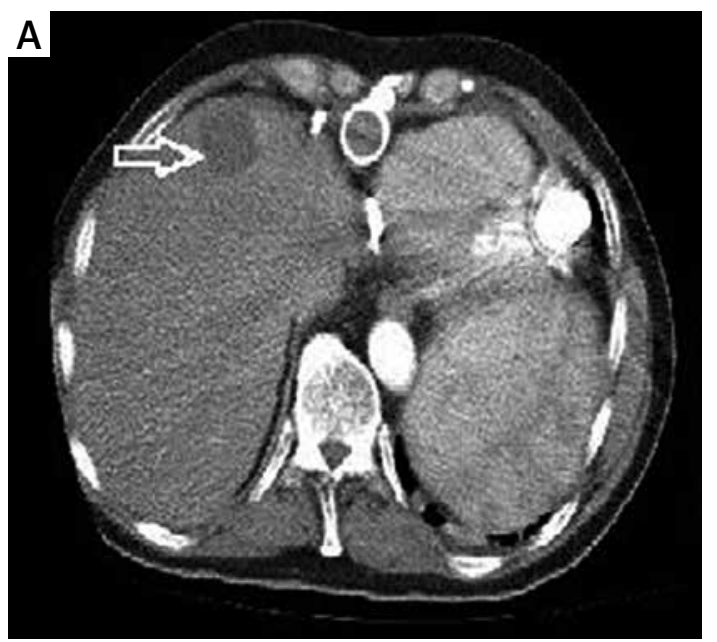

Figure 4. Computed tomography (A) and position emission tomography (B) image of liver metastasis on segment 4A

Today LVADs are being used for many patients in order to treat end-stage cardiac failures, to maintain bridging to transplantation or destination therapy. Malignity screening is recommended before implantation of these devices in an elective condition [2]. As was the case with our patient, however, this is not always possible in cases of unexpected decompensated heart failure which is unresponsive to medical treatment. The LVAD implantation is recommended if malignancy-re-
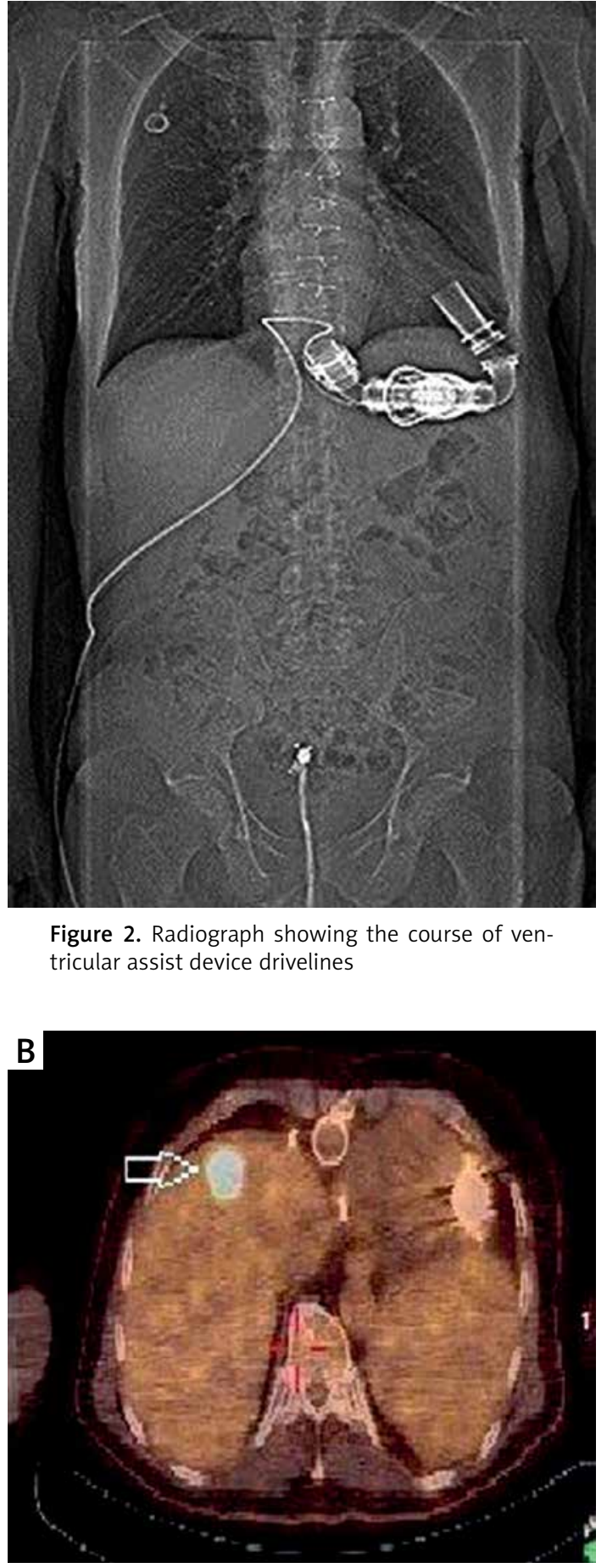

Figure 2. Radiograph showing the course of ventricular assist device drivelines

lated survival expectancy is 2 years or more [3]. Patients can be on a transplantation waiting list for a long time because of available organ limitation while they have LVADs and they might face non-cardiac pathologies necessitating major surgical procedures within this period. Studies, which have demonstrated that long-term survival could be rendered possible through safe abdominal surgical procedures in patients with LVADs, are encouraging $[4,5]$. Despite a complex surgical proce- 
dure, surgery-related complications and CRT load, the 29-month survival in our patient, who was diagnosed with rectal cancer while he had LVAD, proved to be a long period, and his case showed parallels with stage IIIC rectal cancer cases with no comorbidities [6]. We did not come across any other cases in the literature of patients who received multidisciplinary treatment because of rectal cancer simultaneously with LVAD.

In conclusion, possible malignancies should be detected through a comprehensive screening program in patients with end-stage heart failure before they are included on transplantation waiting lists. We believe that patients who were not included in screening programs or who contracted malignancies during the time they were living with ventricular support devices should be treated without compromising any oncological principles at centers with cardiac experience.

\section{Conflict of interest}

The authors declare no conflict of interest.

\section{References}

1. Davis J, Sanford D, Schilling J, Hardi A, Colditz G. Systematic review of outcomes after noncardiac surgery in patients with implanted left ventricular assist sevices. ASAIO I 2015; 61: 648-51.

2. Garatti A, Bruschi G, Colombo T, et al. Noncardiac surgical procedures in patient supported with long-term implantable left ventricular assist device. Am J Surg 2009; 197: 710-4.

3. Feldman D, Pamboukian SV, Teuteberg JJ, et al. The 2013 International Society for Heart and Lung Transplantation Guidelines for mechanical circulatory support: executive summary. J Heart Lung Transplant 2013; 32: 157-87.

4. Arnaoutakis GJ, Bittle GJ, Allen JG, et al. General and acute care surgical procedures in patients with left ventricular assist devices. World I Surgery 2014; 38: 765-73.

5. Barbara DW, Wetzel DR, Pulido JN, et al. The perioperative management of patients with left ventricular assist devices undergoing noncardiac surgery. Mayo Clin Proc 2013; 88: 674-82.

6. NCCN Clinical Practice Guidelines in Oncology. Rectal cancer.2015. Available at: http://www.nccn.org.Accessed: June 18, 2015. 